\title{
Action Spectroscopy of Deprotomer-Selected Hydroxycinnamate Anions
}

\author{
James N. Bull • Jack T. Buntine - Eduardo Carrascosa • Mark H. \\ Stockett • Evan J. Bieske
}

Received: date / Accepted: date

\begin{abstract}
Tandem ion mobility mass spectrometry coupled laser excitation is used to record photodetachment, photoisomerization and photodepletion action spectra for a series of deprotomer-selected hydroxycinnamate anions, including deprotonated caffeic, ferulic and sinapinic acids. This molecular series accounts for most hydroxycinnamic moieties found in nature. Phenoxide deprotomers for para and ortho structural isomers have similar photodetachment action spectra that span the $350-460 \mathrm{~nm}$ range with the maximum response occurring between 420 and $440 \mathrm{~nm}$. None of the phenoxide deprotomers showed evidence for $E \rightarrow Z$ photoisomerization. In contrast, photoexcitation of the carboxylate deprotomers of caffeic and ferulic acids and the meta-phenoxide deprotomer of caffeic acid initiates intramolecular proton transfer to give the para-phenoxide deprotomer. Photoexcitation of the carboxylate deprotomer of sinapinic acid and ortho-coumaric acid does not result in intramolecular proton transfer, presumably due to substantial barriers for rearrangement. For deprotonated meta-coumaric acid, interconversion between the phenoxide and carboxylate deprotomers oc-
\end{abstract}

\footnotetext{
J. N. Bull

School of Chemistry, Norwich Research Park, University of East Anglia, Norwich NR4 7TJ, United Kingdom

J. T. Buntine \& E. J. Bieske

School of Chemistry, University of Melbourne, Parkville, VIC 3010, Australia

E. Carrascosa

Laboratoire de Chimie Physique Moléculaire, École Polytechnique Fédérale de Lausanne, EPFL SB ISIC LCPM, Station 6, CH-1015 Lausanne, Switzerland

M. H. Stockett

Department of Physics, Stockholm University, SE-10691

Stockholm, Sweden
}

curs in the ion mobility spectrometer drift region where the effective ion temperature is $T_{\text {eff }} \approx 299 \mathrm{~K}$.

Keywords Ion mobility · Photodetachment spectroscopy $\cdot$ Isomers $\cdot$ Proton migration

\section{Introduction}

Molecules based on the para-hydroxycinnamate moiety are widespread in nature.[1] For example, a thioester derivative of para-coumaric acid is the biochromophore in photoactive yellow protein (PYP), $[2,3,4]$ while sinapinic acid (often called sinapic acid) and the methyl ester are models for sinapoyl malate, which is a UV-B sunscreen found in plant leaves. [5] Caffeic and ferulic acids are ubiquitous in seeds and leaves in both their free form and covalently bound to cell walls and lignin structures.[6]

A desire to understand the absorption properties, excited state dynamics, and $E \rightarrow Z$ photoisomerization responses of hydroxycinnamate molecules and their deprotonated anions has prompted numerous experimental and theoretical investigations. Studies considering hydroxycinnamate molecules in solution have revealed complex internal conversion dynamics in which the $E \rightarrow Z$ photoisomerization quantum yield depends on solvent polarity, viscosity and $\mathrm{pH} .[7,8,9,10,11,12,13]$ Theoretical studies have suggested that the molecules' excited state potential energy surfaces and conical intersection seams are strongly affected by solvation and charge state.[14, 15, 16, 17, 18, 19, 20, 21, 22] For example, on the basis of excited state molecular dynamic simulations, Robb and co-workers hypothesized that $E \rightarrow Z$ photoisomerization of the chromophore in PYP is enhanced by protein side-group interactions. [14, 15] 


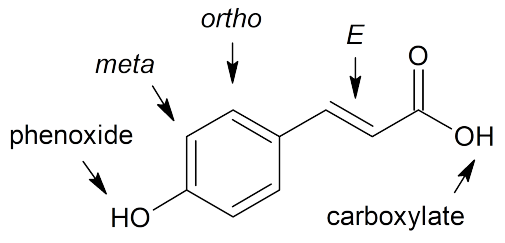

Fig. 1 Structure of (E)-para-coumaric acid $[(E)-p \mathrm{CA}]$. The two deprotonation sites lead to phenoxide $\left(\mathrm{O}^{-}\right)$and carboxylate $\left(\mathrm{COO}^{-}\right)$deprotomers. ortho and meta substitution sites are identified. For methyl esters, the -COOH carboxylate group is replaced by a $-\mathrm{COOCH}_{3}$ methyl ester group.

There have been numerous gas-phase investigations focussing on the spectroscopy and dynamics of the first excited state of deprotonated hydroxycinnamate anions formed using electrospray ionization. The principal motivation for gas-phase studies is that they address a molecule's inherent photochemistry, allowing for straight-forward comparison between experiment and theory.[23] Gas-phase studies also provide a baseline for understanding the influence of solvation or protein side-group interactions.[24] Previous gas-phase studies on deprotonated hydroxycinnamate molecules include photodissociation action spectroscopy to infer absorption spectra, $[25,26,27,28]$ photodetachment and photoelectron spectroscopy to infer absorption spectra and excited state dynamics, [29] and femtosecond time-resolved photoelectron spectroscopy to map the evolution of the excited state population. [30, 31, 32]

In a recent study, we coupled tandem ion mobility spectrometry and laser excitation to show that electrospray of para-coumaric acid (Fig. 1) produces phenoxide $\left(\mathrm{O}^{-}\right)$and carboxylate $\left(\mathrm{COO}^{-}\right)$deprotomers in their $E$ isomeric forms.[33] We also showed that the deprotomers have distinct photoresponses and action spectra. In ion mobility spectrometry (IMS), charged isomers (e.g. $E$ and $Z$ geometric isomers and deprotomers) drifting under the influence of an electric field through a buffer gas are separated according to their drift speeds, which depend on their collision cross-sections. [34] In the IMS-photo-IMS strategy, a target isomer is selected in a primary IMS stage and then exposed to wavelength tunable light, with separation of photoisomers or photofragments in a second IMS stage. Photo-induced electron detachment can be detected sensitively by seeding the buffer gas in the drift region with a trace amount of $\mathrm{SF}_{6}$ (an efficient electron scavenger) and monitoring the yield of $\mathrm{SF}_{6}{ }^{-}$. [35] The isomer selectivity provided by IMS-photo-IMS action spectroscopy avoids complications associated with overlapping spectra of coexisting isomers that potentially complicate other action spectroscopy techniques. For deprotonated paracoumaric acid $\left(p \mathrm{CA}^{-}\right)$, we showed that the phenox- ide deprotomer $\left[(E)-p \mathrm{CA}^{-}\left(\mathrm{O}^{-}\right)\right]$photodetached over the $350-460 \mathrm{~nm}$ range with no evidence for $E \rightarrow Z$ photoisomerization. In contrast, photoexcitation of the (E)- $p \mathrm{CA}^{-}\left(\mathrm{COO}^{-}\right)$deprotomer over the $290-380 \mathrm{~nm}$ range produced two photoisomers, which were assigned to the $(E)-p \mathrm{CA}^{-}\left(\mathrm{O}^{-}\right)$deprotomer and a $(E)$-keto$p \mathrm{CA}^{-}$tautomer. The proton transfer mechanism was attributed to an initial phototautomerization to give the $(E)$-keto- $p \mathrm{CA}^{-}$tautomer, followed by statistical isomerization to give the $(E)-p \mathrm{CA}^{-}\left(\mathrm{O}^{-}\right)$deprotomer. The methyl ester, $(E)-p \mathrm{CEs}^{-}$, also showed no $E \rightarrow Z$ photoisomerization. The lack of an $E \rightarrow Z$ photoisomerization response for the phenoxide form is consistent with recent single-colour photoelectron spectroscopy and femtosecond time-resolved photoelectron spectroscopy measurements on $(E)-p \mathrm{CEs}^{-}$, which showed that autodetachment is more rapid than ground state recovery. [31, 29] A similar conclusion was reached in earlier molecular dynamics simulations on the thioester derivative. $[14,15]$

This paper details application of IMS-photo-IMS action spectroscopy to a series of para-hydroxycinnamate anions, including deprotonated caffeic, ferulic and sinapinic acid, and the methyl ester of each species. Deprotonated ortho- and meta-coumaric acid were also investigated. The study addresses four questions: (1) Can the different deprotomers of substituted parahydroxycinnamate anions be distinguished using ion mobility spectrometry? (2) Do the target anions photoisomerize or photodetach in the gas phase? (3) Can deprotomer-specific action spectra be measured? (4) Does substitution on the aromatic ring affect the deprotomer rearrangement processes recently postulated for $(E)-p \mathrm{CA}^{-}\left(\mathrm{COO}^{-}\right)$?

\section{Experimental methods}

Hydroxycinnamic acid samples were purchased from Sigma-Aldrich (Castle Hill, $>99 \%$ purity as the $E$ isomer). Methyl ester derivatives were synthesized through Fischer esterification by dissolving the precursor acid in methanol and heating to $\approx 50^{\circ} \mathrm{C}$ with vigorous stirring for 24 hours. In all cases, the reaction product yield was $>95 \%$.

Experiments were performed using a tandem IMS-IMS-QMF instrument that has been described previously,[36] where IMS is an ion mobility spectrometry drift region and QMF is a quadrupole mass filter. Briefly, a solution of $\approx 10^{-3}$ mol L ${ }^{-1}$ sample dissolved in methanol was pumped by a syringe through a silica capillary (flow rate $\approx 10 \mu \mathrm{L} \mathrm{min}^{-1}$ ) to an electrospray source operated at $-3.3 \mathrm{kV}$. Electrosprayed ions were 
transferred via a heated capillary into a $\mathrm{RF}$ ion funnel (IF1), which gathered the ions and focused them towards an electrostatic ion gate (IG1) that injected $\approx 100 \mu$ s packets of ions at $40 \mathrm{~Hz}$ into the first drift region. In the drift region, the ions were propelled by an electric field $\left(44 \mathrm{~V} \mathrm{~cm}^{-1}\right)$ through buffer gas consisting of $\mathrm{N}_{2}$ at a pressure of $\approx 6$ Torr that could be seeded with a trace amount of $\mathrm{SF}_{6}$. Isomers were separated spatially and temporally because of differences in their collision cross-sections. At the end of the second drift region, an ion funnel collected the ions and introduced them into a differentially pumped octupole ion guide followed by a QMF that mass selected the ions before they reached a Channeltron detector. The detector was connected to a multichannel scaler that produced a histogram of ion counts against arrival time, corresponding to an arrival time distribution (ATD). In all ATDs presented in this paper, $t=0$ corresponds to the opening of IG1.

For the photochemistry experiments, a BradburyNielsen ion gate (IG2) situated between the two drift regions was opened briefly (for $\approx 100 \mu \mathrm{s}$ ) to transmit mobility-selected anions. The gated ions were exposed to a light pulse from a tunable optical parametric oscillator (OPO, EKSPLANT342B), which induced photoisomerization or photodetachment. The OPO was operated at $20 \mathrm{~Hz}$, half the rate of ion injection, allowing accumulation of light-on and light-off ATDs. The light fluence was limited to $<0.3 \mathrm{~mJ} \mathrm{~cm}{ }^{-2}$ pulse $^{-1}$ which gave no more than $\approx 4 \%$ total photoresponse (and no photodissociation). Following irradiation, the parent and photoproduct ions were separated according to their collision cross-sections in the second drift region. Photodetachment from the target anions was detected by seeding the buffer gas with a trace of $\mathrm{SF}_{6}$, which acted as an electron scavenger, and monitoring the yield of $\mathrm{SF}_{6}{ }^{-}$. [33] One limitation was that ultraviolet light striking the metal drift electrodes generated photoelectrons and a $\mathrm{SF}_{6}{ }^{-}$background signal. This restricted the wavelength range of photodetachment action spectra recorded in this way to $\lambda \geq 370 \mathrm{~nm}$. Action spectra were generated by plotting the light-on - light-off or 'photoaction' signal for a given product (normalized to light pulse fluence and light-off signal) against wavelength of the excitation light.

It is important to note that ions in the drift region are photoactivated in an environment where the collision rate is $\approx 10^{9} \mathrm{~s}^{-1}$ at 6 Torr. This influences which processes are observed. [33, 37, 38] Rapid excited state processes occurring on sub-nanosecond timescales, including photoisomerization by passage through a conical intersection or autodetachment, will tend to take place. On the other hand, slower ground state processes such as statistical dissociation or statistical electron ejection (thermionic emission), may be suppressed because of collisional deactivation.

It is worth stating that the ATDs shown in this paper were measured over several days. Because of slight day-to-day variations in the partial pressures of $\mathrm{N}_{2}$ and $\mathrm{SF}_{6}$, the ATDs for different species are not directly comparable. The collision cross-sections for all observed isomers were measured in pure $\mathrm{N}_{2}$ buffer gas over a single day.

\section{Theoretical methods}

Electronic structure calculations were performed using the Gaussian 16.B01 and ORCA 4.2.0 software packages.[39, 40] Geometry optimizations, vibrational frequencies and zero-point energies were computed at the $\omega$ B97X-D/aug-cc-pVTZ level of theory followed by single-point energy calculations at the DLPNOCCSD(T)/aug-cc-pVTZ level of theory.[41, 42, 43]

Collision cross-sections were modelled using the trajectory method in MOBCAL parametrized for $\mathrm{N}_{2}$ buffer gas.[44] Input charge distributions were computed at the $\omega$ B97X-D/aug-cc-pVTZ level of theory with the Merz-Singh-Kollman scheme constrained to reproduce the electric dipole moment.[45] Sufficient trajectories were computed to give standard deviations of $\pm 1 \AA^{2}$ for the calculated values.

\section{Results and discussion}

\section{1 $\mathrm{CA}^{-}$and $\mathrm{CEs}^{-}$}

\subsubsection{Deprotomers}

The first set of target anions included deprotonated caffeic acid $\left(\mathrm{CA}^{-}\right)$and the methyl ester $\left(\mathrm{CEs}^{-}\right)$whose structure are shown in Fig. 2. CA has three deprotonation sites leading to the para-phenoxide $\left(\mathrm{O}^{-}\right)$, metaphenoxide $\left(\mathrm{mO}^{-}\right)$, and carboxylate $\left(\mathrm{COO}^{-}\right)$deprotomers. ATDs for electrosprayed $\mathrm{CA}^{-}$and $\mathrm{CEs}^{-}$are shown in Fig. 3a and b, respectively. The ATD for $\mathrm{CA}^{-}$exhibits three peaks, which are assigned to the $E$ isomers for the three deprotomers based on calculated energies (Table 1), variation of isomer abundances with first ion funnel (IF1) RF drive voltage, and measured $\left(\Omega_{m}\right)$ vs calculated $\left(\Omega_{c}\right)$ collision cross-sections (Table 1). The assignments are consistent with results for ferulic and sinapinic acid in the next section. Briefly, a low RF drive voltage applied to IF1 ('IF1 low' ATDs in Fig. 3) produces an ATD that reflects the nascent electrosprayed isomer populations. In contrast, a high RF drive voltage applied to IF1 ('IF1 high' ATDs in 
Fig. 3) significantly increases ion throughput but also induces energetic collisions between the ions and buffer gas molecules that promotes conversion of the isomers to the most stable gas-phase form.[33] For $\mathrm{CA}^{-}$, a high RF drive voltage applied to IF1 gave a single ATD peak assigned to the $(E)-\mathrm{CA}^{-}\left(\mathrm{O}^{-}\right)$deprotomer. Note that under 'IF1 low' conditions, $Z$ isomers are not expected since the electrosprayed solution contained $>99 \%$ pure $E$ isomer. Irradiation of the solution in the electrospray syringe with a blue or near-UV LED immediately before recording the IF1 low ATD gave no discernible change to the ATD, [46] indicating that any $Z$ photoisomers formed in methanol solution thermally revert to the $E$ isomers on a timescale shorter than a few seconds - similar observations were made for all hydroxycinnamate molecules in this study.

ATDs for $\mathrm{CEs}^{-}$are shown in Fig. 3c. With a low $\mathrm{RF}$ drive voltage applied to IF1 there are two peaks assigned to the $(E)-\mathrm{CEs}^{-}\left(\mathrm{O}^{-}\right)$and $(E)-\mathrm{CEs}^{-}\left(m \mathrm{O}^{-}\right)$ deprotomers - see relative energies and collision crosssections in Table 1. The 'IF1 high' ATD exhibits only one ATD peak consistent with the $(E)-\mathrm{CEs}^{-}\left(\mathrm{O}^{-}\right)$ deprotomer.

\subsubsection{Action spectroscopy}

Photoaction (light-on - light-off) ATDs at selected wavelengths for mobility-selected $\mathrm{CA}^{-}$and $\mathrm{CEs}^{-}$ species are shown in Fig. $3 \mathrm{a}-\mathrm{c}$. Ions associated with ATD peaks assigned to $(E)-\mathrm{CA}^{-}\left(\mathrm{O}^{-}\right)$and $(E)-\mathrm{CEs}^{-}$ $\left(\mathrm{O}^{-}\right)$undergo photodetachment to yield $\mathrm{SF}_{6}{ }^{-}$with no evidence for $E \rightarrow Z$ photoisomerization (see photoaction
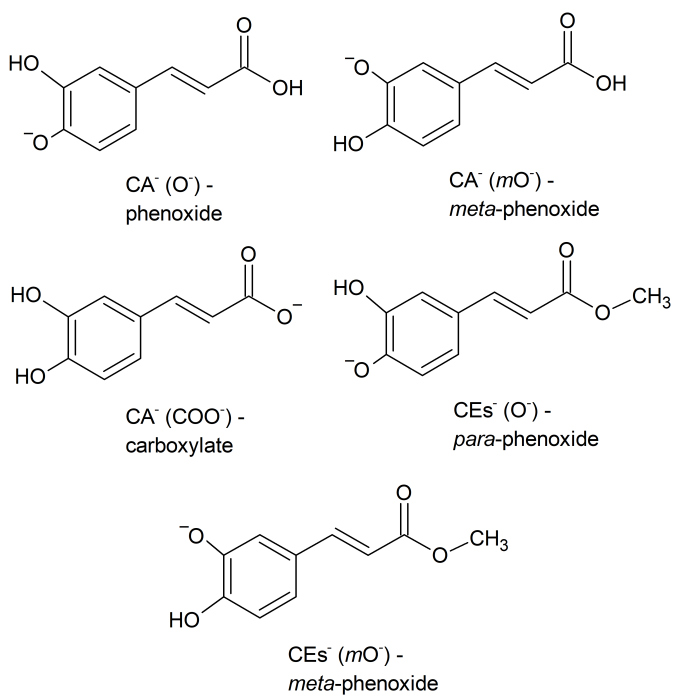

Fig. $2 E$ isomers of deprotonated caffeic acid molecules. Key: CA - caffeic acid, CEs - caffeic methyl ester. $\mathrm{O}^{-}, \mathrm{mO}^{-}$ and $\mathrm{COO}^{-}$indicates para-phenoxide, meta-phenoxide and carboxylate deprotomers.

\begin{tabular}{|c|c|c|c|}
\hline Species & $E$ & $\Omega_{c} / \AA^{2}$ & $\Omega_{m}( \pm 10) / \AA^{2}$ \\
\hline \multicolumn{4}{|l|}{ Caffeic acid species } \\
\hline$(E)-\mathrm{CA}^{-}\left(\mathrm{O}^{-}\right)$ & 0 & 134 & 128 \\
\hline$(Z)-\mathrm{CA}^{-}\left(\mathrm{O}^{-}\right)$ & 22 & 134 & - \\
\hline$(E)-\mathrm{CA}^{-}\left(m \mathrm{O}^{-}\right)$ & 16 & 137 & 139 \\
\hline$(Z)-\mathrm{CA}^{-}\left(\mathrm{mO}^{-}\right)$ & 41 & 136 & - \\
\hline$(E)-\mathrm{CA}^{-}\left(\mathrm{COO}^{-}\right)$ & 13 & 149 & 147 \\
\hline$(Z)-\mathrm{CA}^{-}\left(\mathrm{COO}^{-}\right)$ & 66 & 148 & - \\
\hline$(E)-\mathrm{CEs}^{-}\left(\mathrm{O}^{-}\right)$ & 0 & 137 & 137 \\
\hline$(Z)-\mathrm{CEs}^{-}\left(\mathrm{O}^{-}\right)$ & 49 & 136 & - \\
\hline$(E)-\mathrm{CEs}^{-}\left(m \mathrm{O}^{-}\right)$ & 21 & 143 & 144 \\
\hline$(Z)-\mathrm{CEs}^{-}\left(m \mathrm{O}^{-}\right)$ & 49 & 143 & - \\
\hline \multicolumn{4}{|l|}{ Ferulic acid species } \\
\hline$(E)-\mathrm{FA}^{-}\left(\mathrm{O}^{-}\right)$ & 0 & 141 & 133 \\
\hline$(Z)-\mathrm{FA}^{-}\left(\mathrm{O}^{-}\right)$ & 44 & 141 & - \\
\hline$(E)-\mathrm{FA}^{-}\left(\mathrm{COO}^{-}\right)$ & 25 & 151 & 144 \\
\hline$(Z)-\mathrm{FA}^{-}\left(\mathrm{COO}^{-}\right)$ & 56 & 148 & - \\
\hline$(E)-\mathrm{FEs}^{-}$ & 0 & 148 & 144 \\
\hline$(Z)-\mathrm{FEs}^{-}$ & 29 & 146 & - \\
\hline \multicolumn{4}{|l|}{ Sinapinic acid species } \\
\hline$(E)-\mathrm{SA}^{-}\left(\mathrm{O}^{-}\right)$ & 0 & 148 & 144 \\
\hline$(Z)-\mathrm{SA}^{-}\left(\mathrm{O}^{-}\right)$ & 29 & 148 & - \\
\hline$(E)-\mathrm{SA}^{-}\left(\mathrm{COO}^{-}\right)$ & 13 & 155 & 154 \\
\hline$(Z)-\mathrm{SA}^{-}\left(\mathrm{COO}^{-}\right)$ & 36 & 154 & - \\
\hline$(E)-\mathrm{SEs}^{-}$ & 0 & 155 & 155 \\
\hline$(Z)-\mathrm{SEs}^{-}$ & 20 & 154 & - \\
\hline \multicolumn{4}{|l|}{ Coumaric acid species } \\
\hline$(E)-o \mathrm{CA}^{-}\left(\mathrm{O}^{-}\right)$ & 0 & 132 & 127 \\
\hline$(Z)-o \mathrm{CA}^{-}\left(\mathrm{O}^{-}\right)$ & 24 & 131 & - \\
\hline$(E)-o \mathrm{CA}^{-}\left(\mathrm{COO}^{-}\right)$ & 17 & 141 & 136 \\
\hline$(Z)-o \mathrm{CA}^{-}\left(\mathrm{COO}^{-}\right)$ & 42 & 139 & - \\
\hline$(E)-o \mathrm{CEs}^{-}$ & 0 & 140 & 141 \\
\hline$(Z)-o \mathrm{CEs}^{-}$ & 34 & 138 & - \\
\hline$(E)-m \mathrm{CA}^{-}\left(\mathrm{O}^{-}\right)$ & 0 & 137 & 136 \\
\hline$(Z)-m \mathrm{CA}^{-}\left(\mathrm{O}^{-}\right)$ & 33 & 137 & - \\
\hline$(E)-m \mathrm{CA}^{-}\left(\mathrm{COO}^{-}\right)$ & 6 & 145 & 146 \\
\hline$(Z)-m \mathrm{CA}^{-}\left(\mathrm{COO}^{-}\right)$ & 12 & 139 & - \\
\hline$(E)-m \mathrm{CEs}^{-}$ & 0 & 145 & 142 \\
\hline$(Z)-m \mathrm{CEs}^{-}$ & 33 & 145 & - \\
\hline
\end{tabular}

Table 1 Energies $(E)$ in $\mathrm{kJ} \mathrm{mol}^{-1}$ relative to the lowest energy isomer, calculated $\left(\Omega_{c}\right)$ and measured collision crosssections $\left(\Omega_{m}\right)$ for deprotonated hydroxycinnamate anions. Key: $\mathrm{CA}^{-}$- caffeic acid, $\mathrm{CEs}^{-}$- caffeic methyl ester, $\mathrm{FA}^{-}$ - ferulic acid, $\mathrm{FEs}^{-}$- ferulic methyl ester, $\mathrm{SA}^{-}$- sinapinic acid, $\mathrm{SEs}^{-}$- sinapinic methyl ester, $o \mathrm{CA}^{-}-$ortho-coumaric acid, $o \mathrm{CEs}^{-}{ }^{-}$ortho-coumaric methyl ester, $m \mathrm{CA}^{-}-$metacoumaric acid, $m \mathrm{CEs}^{-}-$meta-coumaric methyl ester. $\Omega_{m}$ values were determined from measurements in pure $\mathrm{N}_{2}$ buffer gas.

ATDs in Fig. 3a and c), a result that parallels findings for the phenoxide deprotomers of para coumaric acid and its ester $\left(p \mathrm{CA}^{-}\right.$and $\left.p \mathrm{CEs}^{-}\right)$reported in Ref. 33 . The photoaction ATD for the $(E)-\mathrm{CEs}^{-}\left(\mathrm{mO}^{-}\right)$deprotomer (Fig. $3 \mathrm{~b}$ ) shows evidence for isomerization to the $(E)-\mathrm{CEs}^{-}\left(\mathrm{O}^{-}\right)$deprotomer - further support for this assignment is given in the Electronic Supporting Material. Note that the photoisomer ATD peak has an arrival time intermediate between the $\mathrm{O}^{-}$and $m \mathrm{O}^{-}$ peaks since the photoactivated ions are present as one deprotomer in the first IMS drift region and the 

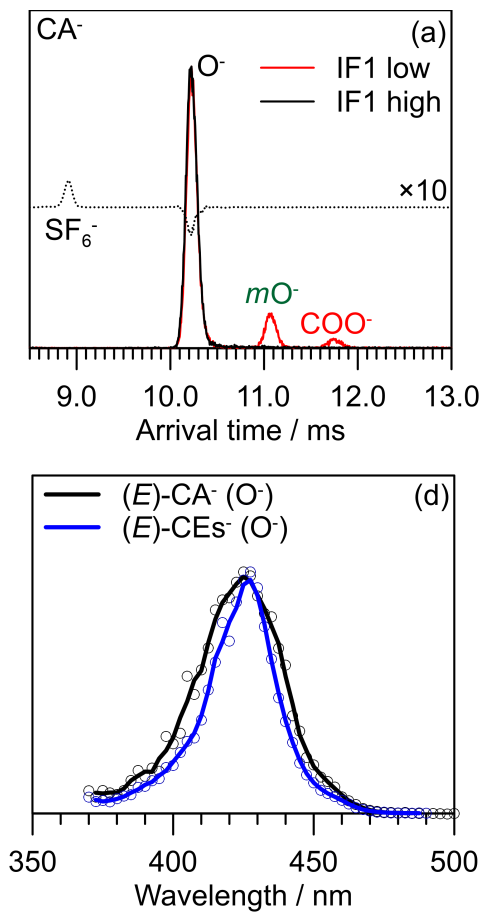
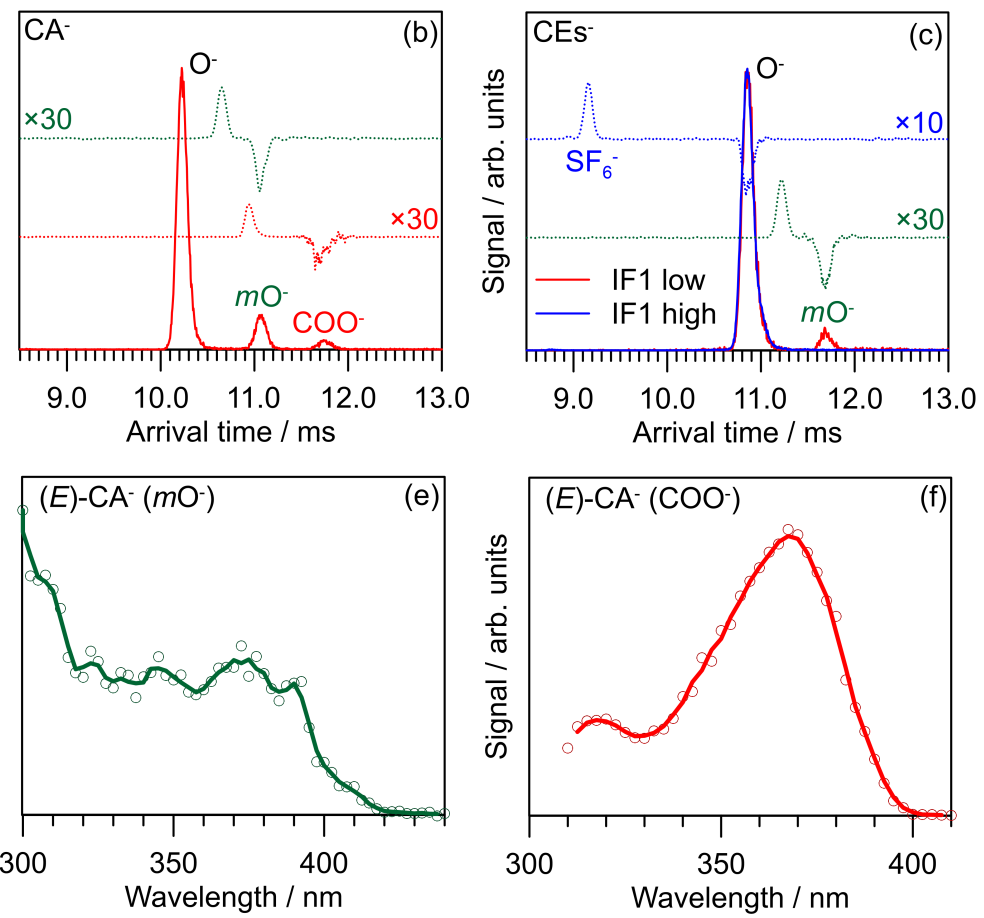

Fig. 3 (a) ATDs recorded for $\mathrm{CA}^{-}$and photoaction ATD for the fast peak [assigned to $\left.(E)-\mathrm{CA}^{-}\left(\mathrm{O}^{-}\right)\right]$at $420 \mathrm{~nm}($ black dashed), (b) IF1 low ATD for $\mathrm{CA}^{-}$and photoaction ATD for the middle peak [assigned to $(E)-\mathrm{CA}^{-}\left(m \mathrm{O}^{-}\right)$] at $370 \mathrm{~nm}$ (green dashed) and the slow peak [assigned to $\left.(E)-\mathrm{CA}^{-}\left(\mathrm{COO}^{-}\right)\right]$at $350 \mathrm{~nm}$ (red dashed), (c) ATDs recorded for $\mathrm{CEs}^{-}$and photoaction ATD for the fast peak [assigned to $(E)-\mathrm{CEs}^{-}\left(\mathrm{O}^{-}\right)$] at $420 \mathrm{~nm}$ (blue dashed) and the slow peak [assigned to $\left.(E)-\mathrm{CEs}^{-}\left(m \mathrm{O}^{-}\right)\right]$at $370 \mathrm{~nm}$ (green dashed), (d) photodetachment action spectra for $(E)-\mathrm{CA}^{-}\left(\mathrm{O}^{-}\right)$and $(E)-\mathrm{CEs}^{-}\left(\mathrm{O}^{-}\right)$, (e) photoisomerization action spectrum for $(E)-\mathrm{CA}^{-}\left(m \mathrm{O}^{-}\right)$, (f) photoisomerization action spectrum for $(E)-\mathrm{CA}^{-}\left(\mathrm{COO}^{-}\right)$.

other deprotomer in the second IMS drift region. The photoaction ATD for the $(E)-\mathrm{CA}^{-}\left(\mathrm{COO}^{-}\right)$isomer in Fig. 3b shows evidence for conversion to the paraphenoxide deprotomer with no sign of conversion to the meta-phenoxide deprotomer or $Z$ isomer.

Photodetachment and photoisomerization action spectra for the $(E)-\mathrm{CA}^{-}\left(\mathrm{O}^{-}\right),(E)-\mathrm{CA}^{-}\left(m \mathrm{O}^{-}\right),(E)$ $\mathrm{CA}^{-}\left(\mathrm{COO}^{-}\right)$and $(E)-\mathrm{CEs}^{-}\left(\mathrm{O}^{-}\right)$species are shown in Fig. 3d-f. The ion signal for the $(E)-\mathrm{CEs}^{-}\left(\mathrm{mO}^{-}\right)$ deprotomer was too low to allow acquisition of an action spectrum. Photodetachment spectra for the two para-phenoxide deprotomers, $(E)-\mathrm{CA}^{-}\left(\mathrm{O}^{-}\right)$and $(E)$ $\mathrm{CEs}^{-}\left(\mathrm{O}^{-}\right)$in Fig. 3d, are similar and have a maximum response at $\approx 425 \mathrm{~nm}$.

The photoisomerization action spectrum for the $(E)-\mathrm{CA}^{-}\left(m \mathrm{O}^{-}\right)$deprotomer occurs in the near-UV and exhibits a shoulder peak at $\approx 370 \mathrm{~nm}$ with the onset of a stronger band below $\approx 320 \mathrm{~nm}$. Similar spectral features are apparent in the photodepletion spectrum of the methyl ester of meta-coumaric acid described in section 4.4 .

The photoisomerization action spectrum for the $(E)-\mathrm{CA}^{-}\left(\mathrm{COO}^{-}\right)$deprotomer in Fig. 3f has maximum response at $\approx 370 \mathrm{~nm}$. This spectrum is similar to the photoisomerization action spectrum for the carboxylate deprotomer of para coumaric acid $\left(p \mathrm{CA}^{-}\right)$reported in Ref. 33 , which also exhibits a maximum at $\approx 370 \mathrm{~nm}$.

The action spectra for deprotomers of $\mathrm{CA}^{-}$provide evidence for a one-way photoisomerization from higher energy deprotomers $\left(\mathrm{mO}^{-}\right.$and $\left.\mathrm{COO}^{-}\right)$to the lowest energy phenoxide deprotomer. In our earlier study on the carboxylate deprotomer of $p \mathrm{CA}^{-}$, a similar oneway isomerization was observed, with the mechanism postulated to involve an intermediate keto tautomer and ensuing statistical isomerization. For $\mathrm{CA}^{-}$, there was no evidence for a keto tautomer or the $(E)-\mathrm{CA}^{-}$ $\left(m \mathrm{O}^{-}\right)$deprotomer which survive passage through the drift region. Although we cannot make any firm statements about the proton transfer mechanism in $\mathrm{CA}^{-}$, it is worth noting that phenoxide and carboxylate deprotomers of meta-coumaric acid (see section 4.4) undergo interconversion in the drift region and consequently must be separated by a low isomerization barrier on the ground electronic state. For $\mathrm{CA}^{-}$, the presence of distinct ATD peaks suggests that isomerization barriers are higher than for $m \mathrm{CA}^{-}$(see Section 4.4) but are sufficiently low that photoactivated ions, if they are formed, undergo statistical isomerization before collisional quenching in the drift region. [33] 
In the present work, ATD peak resolutions for all phenoxide deprotomers (apart from $\mathrm{mCA}^{-}$, see Section 4.4) are $t / \Delta t=80-90$, where $\Delta t$ is the fullwidth-half-maximum parameter for the ATD peak. These peak resolutions are consistent in each case with the presence of a single isomeric form.[36] We have previously demonstrated for other anions that $E$ and $Z$ geometric isomers that differ in collision cross-section by less than $1 \AA^{2}$ in $\mathrm{N}_{2}$ can still give rise to clear photoisomerization signals using the IMS-photo-IMS strategy, and the technique can simultaneously monitor photoisomerization and electron detachment. Overlapping $E$ and $Z$ isomer signals in an ATD can often be distinguished through measurements in different buffer gases such as $\mathrm{CO}_{2}$ or $\mathrm{N}_{2}$ seeded with a dopant molecule such as propan-2-ol, where separation of the isomers is enhanced.[47, 48] ATD measurements in $\mathrm{N}_{2}$ seeded with $\approx 1 \%$ propan-2-ol (not shown) gave similar ATD resolutions with no evidence for $Z$-isomers (see Ref. [33] for $p \mathrm{CA}^{-}$examples.

It is worth noting that the electron scavenger strategy could not be used to obtain action spectra of $\mathrm{CA}^{-}\left(m \mathrm{O}^{-}\right), \mathrm{CA}^{-}\left(\mathrm{COO}^{-}\right)$or $\mathrm{CEs}^{-}\left(\mathrm{COO}^{-}\right)$as their absorption bands lie in the UV. However, photoaction ATDs recorded over a range of wavelengths showed that the photodepletion signal is roughly balanced by the photoisomerization signal, suggesting minimal electron detachment (and dissociation). For the carboxylate deprotomers, this result parallels recent photoelectron spectroscopy studies on the methyl ester and methyl ether of para-coumaric acid which demonstrated that the photoexcited phenoxide form decays through autodetachment over tens of picoseconds with no evidence for internal conversion to the ground electronic state and thus no formation of a stable photoisomer.[29, 31] On the other hand, the carboxylate deprotomer showed efficient internal conversion to the ground electronic state. Thermionic emission (statistical electron ejection from the ground electronic state) from the carboxylate deprotomer will be strongly suppressed in the present experiment due to collisional deactivation in the drift region, explaining the lack of electron detachment signal. There is presumably efficient ground state recovery and similar suppression of thermionic emission for the $\mathrm{CA}^{-}\left(m \mathrm{O}^{-}\right)$deprotomer

\section{2 $\mathrm{FA}^{-}, \mathrm{FEs}^{-}, \mathrm{SA}^{-}$and $\mathrm{SEs}^{-}$}

The second set of target anions were deprotonated ferulic and sinapinic acid and their methyl esters whose structures are shown in Fig. 4. These molecules are derivatives of caffeic acid with methoxy substitution on the meta hydroxy functional group, reducing the number of potential deprotomers. For sinapinic acid, the functional groups prevent formation of a keto tautomer as postulated to be involved in the photoinduced proton transfer mechanism for $p \mathrm{CA}^{-}$. [33]

ATDs for electrosprayed $\mathrm{FA}^{-}, \mathrm{FEs}^{-}, \mathrm{SA}^{-}$and $\mathrm{SEs}^{-}$are shown in Fig. $5 \mathrm{a}, \mathrm{b}$ and c. ATD peaks were assigned considering calculated collision cross-sections and relative energies as for $\mathrm{CA}^{-}$and $\mathrm{CEs}^{-}$(Table 1 ).

The photoaction ATD for the $(E)-\mathrm{FA}^{-}\left(\mathrm{O}^{-}\right)$deprotomer in Fig. 5a (black dashed trace) shows formation of $\mathrm{SF}_{6}^{-}$generated through capture of photodetached electrons. In contrast, the photoaction ATD for the $(E)-\mathrm{FA}^{-}\left(\mathrm{COO}^{-}\right)$deprotomer shows evidence for conversion of the ions to the $(E)-\mathrm{FA}^{-}\left(\mathrm{O}^{-}\right)$deprotomer - further evidence for this assignment is given in the Electronic Supporting Material.

Photoaction ATDs for $(E)-\mathrm{SA}^{-}\left(\mathrm{O}^{-}\right)$and $(E)-\mathrm{SEs}^{-}$ (Fig. $5 \mathrm{c}$ and $\mathrm{d}$ ) both show formation of $\mathrm{SF}_{6}{ }^{-}$. The photoaction ATD for the $(E)-\mathrm{SA}^{-}\left(\mathrm{COO}^{-}\right)$isomer shown in Fig. 5c exhibits a depletion signal, presumably due to photodetachment. Note that the $\mathrm{SF}_{6}{ }^{-}$detection strategy is not suitable for wavelengths in the nearUV due to scattered light generating photoelectrons

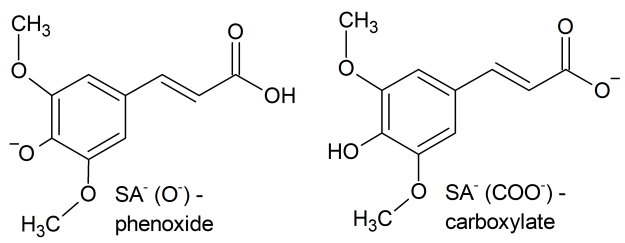<smiles>COC(=O)/C=C/c1cc(OC)c(OC)c(OC)c1</smiles>

Fig. $4 E$ isomers of deprotonated ferulic and sinapinic acid molecules. Key: FA - ferulic acid, FEs - ferulic methyl ester, SA - sinapinic acid, and SEs - sinapinic methyl ester. $\mathrm{O}^{-}$and $\mathrm{COO}^{-}$indicates phenoxide and carboxylate deprotomers. 

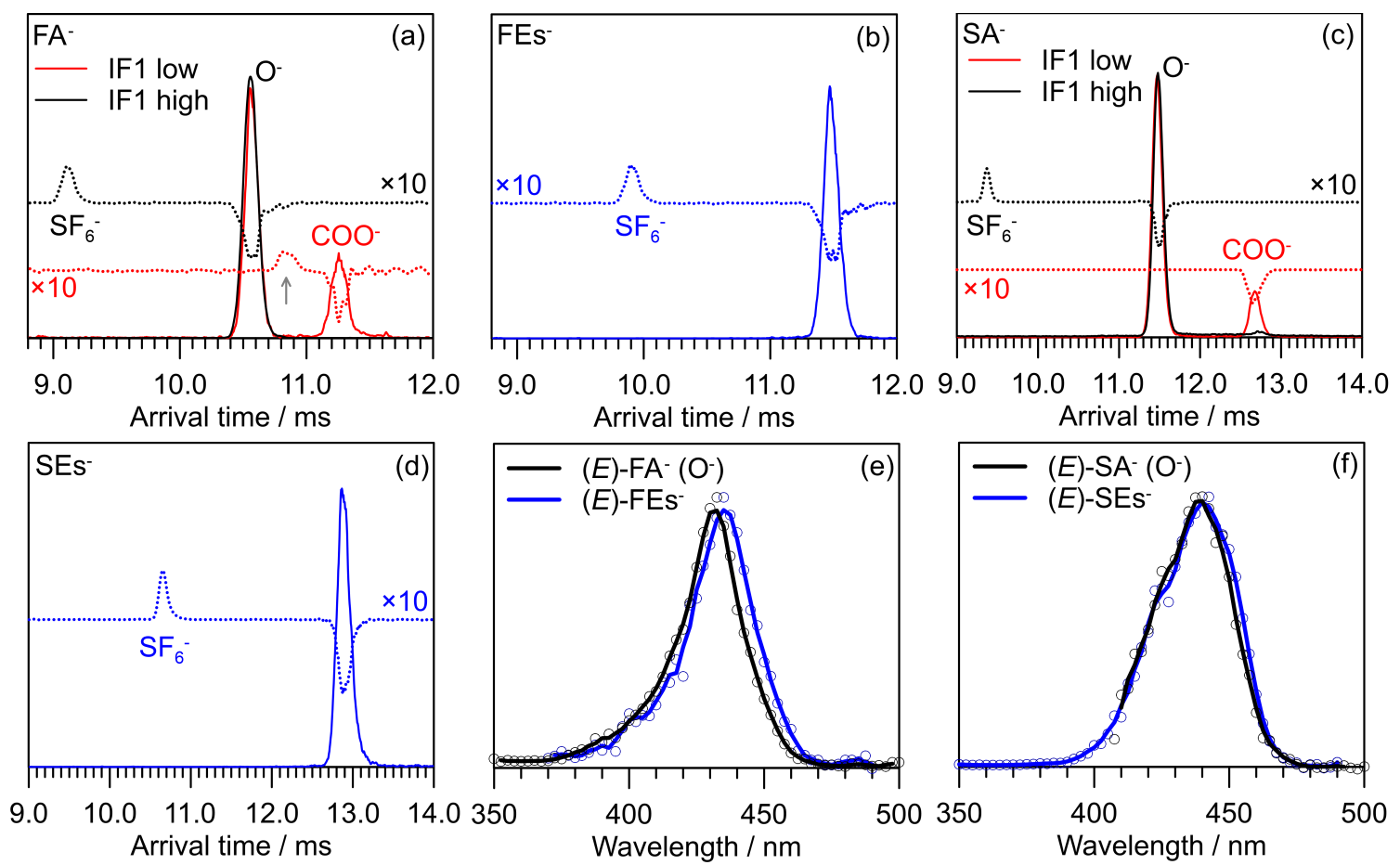

Fig. 5 (a) ATDs for $\mathrm{FA}^{-}$and photoaction ATD for the fast peak [assigned to $(E)-\mathrm{FA}^{-}\left(\mathrm{O}^{-}\right)$] at $420 \mathrm{~nm}$ (black dashed) and slow peak [assigned to $(E)-\mathrm{FA}^{-}\left(\mathrm{COO}^{-}\right)$] at $350 \mathrm{~nm}$ (red dashed), (b) ATD and photoaction ATD at $420 \mathrm{~nm}$ for FEs ${ }^{-},(\mathrm{c})$ ATDs for $\mathrm{SA}^{-}$and photoaction ATD for the fast peak [assigned to $(E)-\mathrm{SA}^{-}\left(\mathrm{O}^{-}\right)$] at $420 \mathrm{~nm}$ (black dashed) and slow peak [assigned to $\left.(E)-\mathrm{SA}^{-}\left(\mathrm{COO}^{-}\right)\right]$at $370 \mathrm{~nm}$ (red dashed), (d) ATD and photoaction ATD at $420 \mathrm{~nm}$ for SEs ${ }^{-}$, (e) photodetachment action spectra for the ATD peaks assigned to $(E)-\mathrm{FA}^{-}\left(\mathrm{O}^{-}\right)$and $(E)-\mathrm{FEs}^{-}$, (f) photodetachment action spectra for the ATD peaks assigned to $(E)-\mathrm{SA}^{-}\left(\mathrm{O}^{-}\right)$and $(E)-\mathrm{SEs}^{-}$.

from the stainless steel drift tube electrodes. In contrast to the carboxylate deprotomers of caffeic and ferulic acid, the $(E)-\mathrm{SA}^{-}\left(\mathrm{COO}^{-}\right)$isomer does not appear to photoisomerize, presumably because the proton transfer mechanism is no longer favourable due to steric hindrance and higher energetic barriers.

Photodetachment action spectra for the $(E)-\mathrm{FA}^{-}$ $\left(\mathrm{O}^{-}\right)$and $(E)-\mathrm{FEs}^{-}$species are shown in Fig. 5e. The photodetachment spectrum for $(E)-\mathrm{FA}^{-}\left(\mathrm{O}^{-}\right)$has maximum response at $\approx 430 \mathrm{~nm}$ while that for $(E)$ $\mathrm{FEs}^{-}$has a slightly red-shifted maximum response at $\approx 435 \mathrm{~nm}$. The photodetachment action spectra for $(E)-\mathrm{SA}^{-}\left(\mathrm{O}^{-}\right)$and $(E)-\mathrm{SEs}^{-}$, shown in Fig. 5f, are essentially identical with maximum response at $\approx 440 \mathrm{~nm}$. The ion signals for $(E)-\mathrm{FA}^{-}\left(\mathrm{COO}^{-}\right),(E)-$ $\mathrm{SA}^{-}\left(\mathrm{COO}^{-}\right)$and $(E)-\mathrm{SEs}^{-}\left(\mathrm{COO}^{-}\right)$deprotomers were too low to acquire action spectra.

\section{$4.3 \circ \mathrm{CA}^{-}$and $o \mathrm{CEs}^{-}$}

The third set of target anions consisted of deprotonated ortho-coumaric acid $\left(o \mathrm{CA}^{-}\right)$and the methyl ester $\left(o \mathrm{CEs}^{-}\right)$whose structures are shown in Fig. 6 . The ATDs for $o \mathrm{CA}^{-}$in Fig. 7a exhibit two peaks, consistent with the presence of phenoxide and carboxylate deprotomers. The ATD for $o \mathrm{CEs}^{-}$(Fig. 7b) shows only one peak consistent with the existence of a single deprotomer. Photoaction ATDs assigned to the $(E)$ $o \mathrm{CA}^{-}\left(\mathrm{O}^{-}\right)$and $(E)-o \mathrm{CEs}^{-}$species indicate that only photodetachment occurs. The photoaction ATD for the $(E)-o \mathrm{CA}^{-}\left(\mathrm{COO}^{-}\right)$deprotomer shows depletion signal with no evidence for photoisomerization at $350 \mathrm{~nm}$, a wavelength at which other carboxylate species showed a photoisomerization response. The lack of a photoiso-<smiles>O=C(O)/C=C/c1ccccc1[O-]</smiles>

$\mathrm{oCA}^{-}\left(\mathrm{O}^{-}\right)$- phenoxide<smiles>O=C([O-])/C=C/c1ccccc1O</smiles>

$\mathrm{oCA}^{-}\left(\mathrm{COO}^{-}\right)$- carboxylate<smiles>COC(=O)/C=C/c1ccccc1[O-]</smiles>

Fig. $6 E$ isomers of deprotonated ortho-coumaric acid molecules. Key: oCA - ortho-coumaric acid, oCEs - orthocoumaric methyl ester. $\mathrm{O}^{-}$and $\mathrm{COO}^{-}$indicates phenoxide and carboxylate deprotomers. 

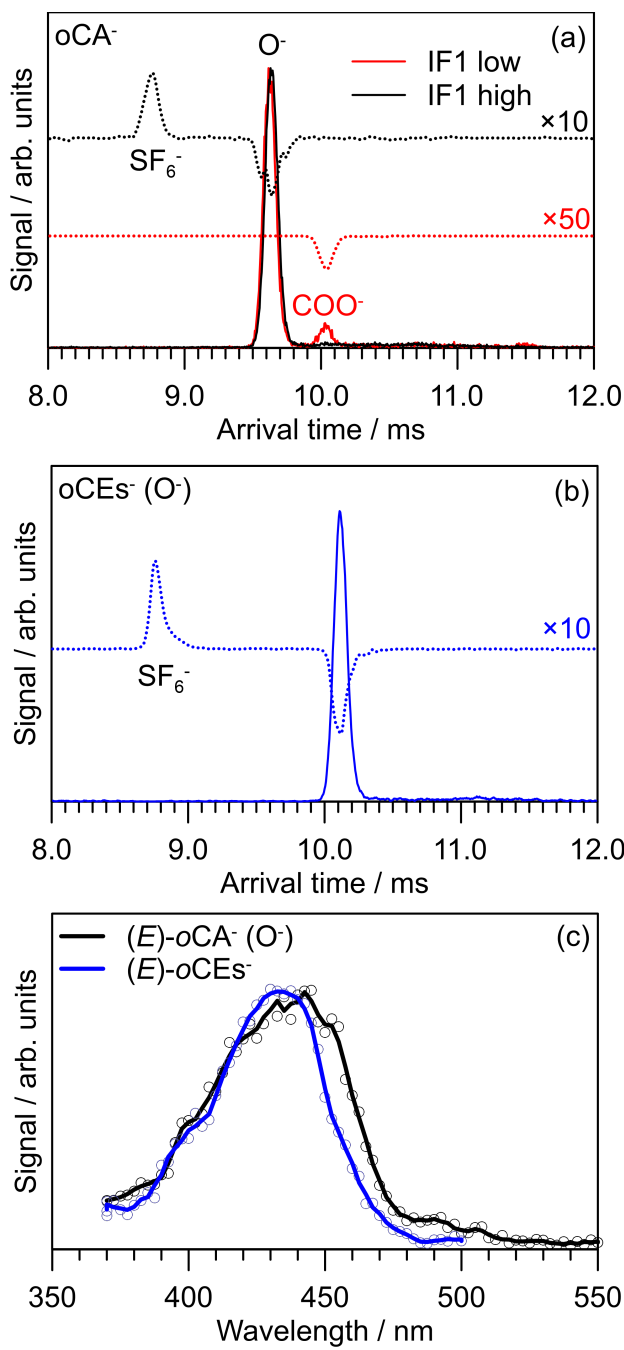

Fig. 7 (a) ATDs for $o \mathrm{CA}^{-}$and photoaction ATD for the fast peak [assigned to $\left.(E)-o \mathrm{CA}^{-}\left(\mathrm{O}^{-}\right)\right]$at $420 \mathrm{~nm}$ (black dashed) and the slow ATD peak [assigned to $(E)-o \mathrm{CA}^{-}$ $\left.\left(\mathrm{COO}^{-}\right)\right]$at $350 \mathrm{~nm}$ (red dashed), (b) ATD for $o \mathrm{CEs}^{-}$and photoaction ATD at $420 \mathrm{~nm}$ for $o \mathrm{CEs}^{-}$(dashed), and (c) photodetachment action spectra for $(E)-o \mathrm{CA}^{-}\left(\mathrm{O}^{-}\right)$and $(E)-o \mathrm{CEs}^{-}$.

mer for the carboxylate deprotomer indicates that the phototautomerisation and deprotomer interconversion mechanism postulated for $p \mathrm{CA}^{-}$does not occur for $o \mathrm{CA}^{-}$.

Photodetachment action spectra for the $(E)-o \mathrm{CA}^{-}$ $\left(\mathrm{O}^{-}\right)$and $(E)-o \mathrm{CEs}^{-}$isomers recorded by monitoring $\mathrm{SF}_{6}{ }^{-}$are shown in Fig. 7c. The spectra have maximum responses at $\approx 440 \mathrm{~nm}$ and $\approx 435 \mathrm{~nm}$, respectively. The spectrum for $(E)-o \mathrm{CEs}^{-}\left(\mathrm{O}^{-}\right)$closely resembles the visible wavelength section of an earlier action spectrum recorded in an ion storage ring. [27] Unfortunately, the ion signal for the $(E)-o \mathrm{CA}^{-}\left(\mathrm{COO}^{-}\right)$deprotomer was too low to acquire an action spectrum.

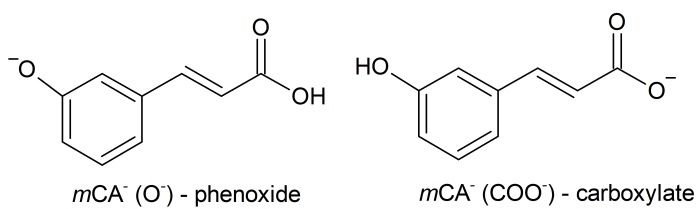<smiles>COC(=O)/C=C/c1cccc(OC)c1</smiles>

Fig. $8 E$ isomers of deprotonated meta-coumaric acid molecules. Key: $m \mathrm{CA}$ - meta-coumaric acid, $m \mathrm{CEs}-$ metacoumaric methyl ester. $\mathrm{O}^{-}$and $\mathrm{COO}^{-}$indicates phenoxide and carboxylate deprotomers.

\section{$4.4 \mathrm{mCA}^{-}$and $m \mathrm{CEs}^{-}$}

Deprotonated meta-coumaric acid $\left(\mathrm{mCA}^{-}\right)$presents a different situation to the deprotonated para or ortho coumaric acid isomers. The ATD for $m \mathrm{CA}^{-}$exhibits two 'bridged' peaks (black trace in Fig. 9a). The form of the ATD, which did not depend on the RF drive voltage applied to IF1, suggests interconversion between two gas-phase forms, presumably phenoxide and carboxylate deprotomers, on a timescale comparable with the drift time through the IMS stages (i.e. milliseconds).[49] Calculations indicate that the $E$ isomers of the two deprotomers differ in energy by only $6 \mathrm{~kJ} \mathrm{~mol}^{-1}$ (Table 1 ). The effective temperature, $T_{e f f}$, of the ions in the drift region is estimated from the low-field expression:[50]

$T_{\text {eff }}=T_{\text {gas }}+\frac{M}{3 k_{B}} v_{d}^{2} \approx 299 \mathrm{~K}$

where $T_{\text {gas }}=294 \mathrm{~K}$ is the buffer gas temperature, $M$ is the mass of $\mathrm{N}_{2}, k_{B}$ is the Boltzmann constant, and $v_{d} \approx 90 \mathrm{~ms}^{-1}$ is the ion speed (estimated from the drift tube length and ion arrival time). The fact that interconversion occurs at essentially room temperature indicates that the interconversion barrier(s) are on the order of $10-30 \mathrm{~kJ} \mathrm{~mol}^{-1}$.

The ATD for $m \mathrm{CEs}^{-}$exhibits one peak, irrespective of drive voltage applied to IF1 (Fig. 7b), which was assigned to $(E)-m \mathrm{CEs}^{-}$. The photoaction ATD shows only photodepletion, which can be attributed to electron detachment. The corresponding photodepletion action spectrum is shown in Fig. 9c with maximum response at $\approx 300 \mathrm{~nm}$. The spectrum closely resembles an earlier photodissociation action spectrum recorded in an ion storage ring. [27]

The $(E)-m \mathrm{CEs}^{-}$and $(E)-\mathrm{CA}^{-}\left(m \mathrm{O}^{-}\right)$action spectra are blue shifted by more than $50 \mathrm{~nm}$ relative to the action spectra for para and ortho coumaric acid phenoxide deprotomers. This shift has been explained 

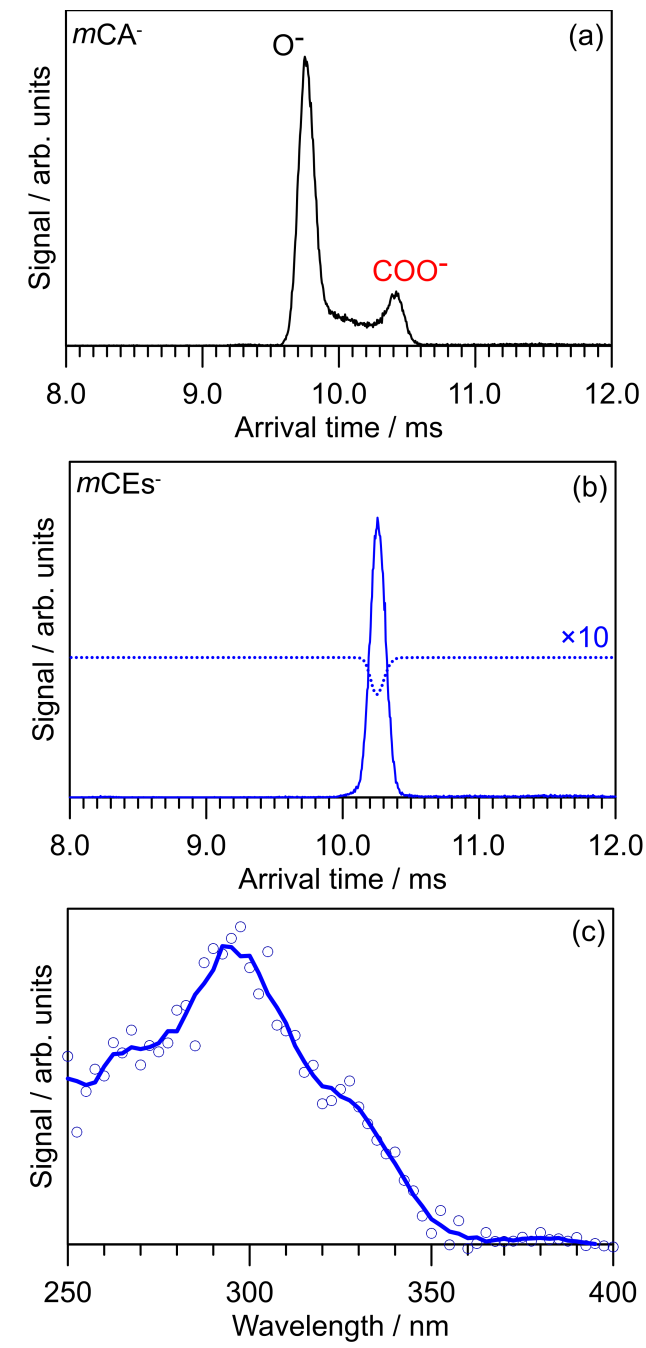

Fig. 9 (a) ATD for $m \mathrm{CA}^{-}$, (b) ATD and photoaction ATD for $m \mathrm{CEs}^{-}$(dashed), (c) photodepletion action spectrum for the ATD peak assigned to $(E)-m \mathrm{CEs}^{-}$. Note, these ATDs and action spectra were recorded in pure $\mathrm{N}_{2}$ buffer gas. Good ion signal for $(E)-m \mathrm{CEs}^{-}$allowed collection of the photodepletion spectrum to shorter wavelengths. Due to poor ion signal, corresponding spectra were not recorded for $(E)$ $\mathrm{CA}^{-}\left(m \mathrm{O}^{-}\right)$or $(E)-\mathrm{CA}^{-}\left(\mathrm{COO}^{-}\right)$.

for $o \mathrm{CEs}^{-}, \mathrm{mCEs}^{-}$and $p \mathrm{CEs}^{-}$in Ref. 27 by considering the conjugation between donor-acceptor groups associated with the electronic transition.[51] For the ortho and para structural isomers, the negative charge on the phenoxide group (donor) is delocalized across the electron withdrawing enoate (or enoic acid for the carboxylic acid) acceptor group, stabilizing the $\pi^{*}$ orbital associated with the $\mathrm{S}_{1}\left(\pi \pi^{*}\right)$ excited state. In contrast, the negative charge on a meta phenoxide group is not delocalized across the acceptor group and therefore the excited state lies at higher energy.

\section{General Discussion and Conclusions}

The available evidence from ATDs, photoaction ATDs, and isomer-selected action spectra for the hydroxycinnamate molecules demonstrate that electrospray ionization generates both phenoxide and carboxylate deprotomers with the relative abundances being sensitive to ion funnel conditions, i.e. collisional excitation before the ions are injected into the drift tube. In accord with earlier studies by our group on para coumaric acid and the corresponding methyl ester and methyl ether, the phenoxide and carboxylate deprotomers of other hydroxycinnamate molecules are readily distinguished using ion mobility spectrometry and their action spectra. The photodetachment action spectra for methyl esters serve as close proxies for the spectra of the phenoxide deprotomers of the corresponding acid molecules. It is worth noting that the $\mathrm{SF}_{6}$ electron scavenger strategy used to record (single photon) photodetachment action spectra is well suited to phenoxide deprotomers of substituted aromatic molecules because their adiabatic electron affinities are in the $\approx 2.4-2.6 \mathrm{eV}$ range, $[33,29]$ and usually lie below the lowest $\pi-\pi^{*}$ transition energy. In contrast, carboxylate deprotomers of these molecules usually have higher electron affinities $(3.2-3.8 \mathrm{eV})$, requiring absorption of several photons to detach an electron if the $\pi-\pi^{*}$ transition of interest lies below the detachment threshold.

All para-phenoxide and ortho-phenoxide deprotomers studied in this work have similar photodetachment action spectra with maximum response in the $420-440 \mathrm{~nm}$ range, indicating that methoxy group substitution on the aromatic ring barely affects the $\pi-\pi^{*}$ electronic structure of the chromophore. Small spectral shifts on the order of $10 \mathrm{~nm}$, are consistent with through-bond electron donating/withdrawing and polarization effects associated with methoxy functional group substitution.[51] For example, the $p \mathrm{CEs}^{-}$ [430 nm] (from Ref. 33), $\mathrm{FEs}^{-}\left(\mathrm{O}^{-}\right)$[435 nm] and $\mathrm{SEs}^{-}$ $\left(\mathrm{O}^{-}\right)[440 \mathrm{~nm}]$ action spectra show that increasing methoxy substitution at the meta ring position is accompanied by a small red shift.

A significant observation is that no phenoxide or carboxylate deprotomer showed evidence for formation of a stable $Z$ isomer through $E \rightarrow Z$ photoisomerization. This may be because autodetachment in the gas phase is more rapid than $E \rightarrow Z$ photoisomerization by passage through a conical intersection, $[14,15,31]$ or alternatively that the $Z$ isomer, if it happens to be formed, spontaneously reverts to the $Z$ isomer in the IMS drift region.

This study has reported photoisomerization, photodetachment and photodepletion spectra for hydrox- 
ycinnamate anions. In cases when electron detachment could be measured using the electron scavenger technique, the $\mathrm{SF}_{6}^{-}$photo-signal closely balanced the parent isomer photodepletion signal, indicating that photodissociation was an insignificant process. The situation was similar for the photoisomerization response, where the depletion of the target isomer was balanced by photoisomer formation. For some species, such as $(E)-m$ CEs, exposure to short wavelength light led to photodepletion which could in principle be due to electron detachment or to photodissociation. We believe that the depletion was probably associated with electron detachment as in no case were photofragments observed, although it is relevant to note that the instrument does not transmit ions with $m / z<80$ and has poor transmission efficiency for ions with $\mathrm{m} / \mathrm{z}$ 80-120. The absence of photofragments, which in a high vacuum environment may be formed following internal conversion and statistical dissociation on the ground state potential energy surface, is possibly due to rapid collisional relaxation of vibrational energy. As outlined in Section 2, the collision rate in the drift region is $\approx 10^{9} \mathrm{~s}^{-1}$, although photoactivated ions probably require hundreds of collisions to thermalize. Collisional quenching means that rapid processes such as autodetachment will tend to take place, whereas slower statistical processes such as dissociation on the ground electronic state following internal conversion may be suppressed. Thus, for the hydroxycinnamate anions, it is likely that photodissociation processes, which may occur in a high vacuum environment, occur more slowly than the electron detachment and do not occur in the drift region. The absence of photodissociation is also consistent with recent time-resolved measurements on the methyl ester of pCA-,[31] which indicate that autodetachment occurs over tens of picoseconds with no evidence for internal conversion to the ground electronic state (required for statistical dissociation processes).

One of the motivations for the present investigation was to determine whether the photo-induced conversion of carboxylate deprotomer to phenoxide deprotomer recently postulated for $p \mathrm{CA}^{-}$is active in ring-substituted para-hydroxycinnamates.[33] While the ion signal for several of the target carboxylate deprotomers was too low to record action spectra, photoaction ATDs at selected near-UV wavelengths were recorded for all carboxylate deprotomers. The carboxylate deprotomer of ferulic acid, which has methoxy substitution at one of the meta sites on $p \mathrm{CA}^{-}$, showed evidence for deprotomer interconversion, although there was no evidence for an intermediate keto tautomer (the intermediate may be short-lived and not survive in the drift region). In contrast, the carboxylate deprotomer of sinapinic acid, which has methoxy groups in both meta positions, showed no evidence for deprotomer interconversion. In principle, these results are consistent with the carboxylate to phenoxide deprotomer interconversion mechanism postulated for $p \mathrm{CA}^{-}$in Ref. [33].

In summary, this study demonstrates the capacity for tandem ion mobility spectrometry coupled with laser spectroscopy to separate deprotomeric forms of hydroxycinnamate molecules and record deprotomerselected action spectra. The technique is best suited to deprotonated (or protonated) molecules that have several low-energy isomeric forms, including larger biological molecules such as lipids, peptides, and polynucleotides. Other key advantages of the technique include the capability to record single-photon action spectra associated with photoisomerization as a proxy for absorption spectra, and the capacity to simultaneously monitor photoisomerization and electron detachment for molecular anions. While recording photodissociation (and photodepletion) response is the most common gasphase action spectroscopy strategy applied to electrosprayed ions and has been coupled with ion mobility spectrometry by several groups, $[52,53,54,55,56,57$, $58]$ many potential target molecules have dissociation thresholds situated higher in energy than the electronic transitions of interest, requiring absorption of several photons to produce a photoresponse. This situation is particularity relevant for biochromophores and technological molecules because they typically absorb in the visible part of the electromagnetic spectrum.

\section{Appendix}

The correlation between calculated $\left(\Omega_{c}\right)$ and measured $\left(\Omega_{m}\right)$ collision cross-sections for the hydroxycinnamates anions studied in this work is shown in Fig. 10. The calculated collision cross-sections are for the lowest energy (equilibrium) geometry. Gas-phase ions in the drift region will undergo internal rotation about single bonds and exhibit fluxionality of methoxy groups. Molecular dynamics simulations and conformationally averaged calculated collision cross-sections are necessary to treat fluxionality more realistically.

Acknowledgements This research was supported under the Australian Research Council's Discovery Project funding scheme (DP150101427 and DP160100474) and Swedish Foundation for International Cooperation in Research and Higher Education (STINT, grant number PT2017-7328). JTB acknowledges The University of Melbourne for a Melbourne Research Scholarship (MRS) and the Australian Government for an Australian Research Training Program Scholarship (RTP). EC acknowledges support by the Austrian Science Fund (FWF) through a Schrödinger Fellowship (Nr. J4013- 


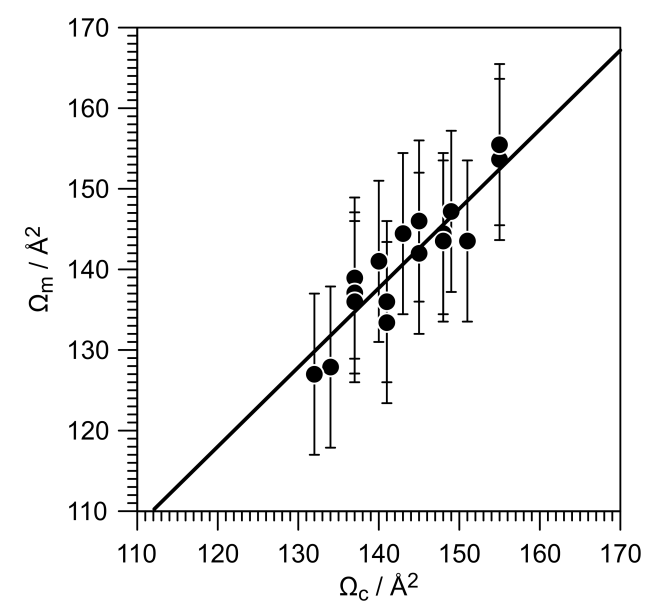

Fig. 10 Correlation between calculated $\left(\Omega_{c}\right)$ and measured $\left(\Omega_{m}\right)$ collision cross-sections in pure $\mathrm{N}_{2}$ buffer gas - see Table 1 . The best fit line indicates that theory overestimates experiment by $\approx 3 \%$. Absolute uncertainty in $\Omega_{m}$ is $\pm 10 \AA^{2}$, however, relative uncertainties are much lower at approximately $\pm 1 \AA^{2}$.

N36). Electronic structure calculations were carried out on the High Performance Computing Cluster supported by the Research and Specialist Computing Support service at the University of East Anglia.

Author contributions Experiments were performed by all authors. Calculations were performed by JNB. The manuscript was drafted by JNB with contributions from all authors.

\section{References}

1. K. Pei, J. Ou, J. Huang, S. Ou, J. Sci. Food Agricult. 96, $2952(2016)$

2. T. Meyer, Biochim. Biophys. Acta - Bioenergetics 806, $175(1985)$

3. T.E. Meyer, E. Yakali, M.A. Cusanovich, G. Tollin, Biochem. 26, 418 (1987)

4. W.W. Sprenger, W.D. Hoff, J.P. Armitage, K.J. Hellingwerf, J. Bacteriol. 175, 3096 (1993)

5. L.A. Baker, M.D. Horbury, S.E. Greenough, F. Allais, P.S. Walsh, S. Habershon, V.G. Stavros, J. Phys. Chem. Lett. 7, 56 (2016)

6. J. Ralph, Phytochem. Rev. 9, 65 (2010)

7. P. Changenet-Barret, A. Espagne, S. Charier, J.B. Baudin, L. Jullien, P. Plaza, K.J. Hellingwerf, M.M. Martin, Photochem. Photobiol. Sci. 3, 823 (2004)

8. H. El-Gezawy, W. Rettig, A. Danel, G. Jonusauskas, J. Phys. Chem. B 109, 18699 (2005)

9. A. Espagne, D.H. Paik, P. Changenet-Barret, M.M. Martin, A.H. Zewail, ChemPhysChem 7, 1717 (2006)

10. A. Espagne, P. Changenet-Barret, P. Plaza, M.M. Martin, J. Phys. Chem. A 110, 3393 (2006)

11. A.D. Stahl, M. Hospes, K. Singhal, I. van Stokkum, R. van Grondelle, M.L. Groot, K.J. Hellingwerf, Biophys. J. 101, 1184 (2011)

12. H. Kuramochi, S. Takeuchi, T. Tahara, J. Phys. Chem. Lett. 3, 2025 (2012)

13. P. Changenet-Barret, F. Lacombat, P. Plaza, J. Photochem. Photobiol. A: Chem. 234, 171 (2012)
14. G. Groenhof, M. Bouxin-Cademartory, B. Hess, S.P. de Visser, H.J.C. Berendsen, M. Olivucci, A.E. Mark, M.A. Robb, J. Am. Chem. Soc. 126, 4228 (2004)

15. G. Groenhof, L.V. Schäfer, M. Boggio-Pasqua, H. Grubmüller, M.A. Robb, J. Am. Chem. Soc. 130, 3250 (2008)

16. E.V. Gromov, I. Burghardt, J.T. Hynes, H. Köppel, L.S. Cederbaum, J. Photochem. Photobiol. A: Chem. 190, $241(2007)$

17. C. Ko, A.M. Virshup, T.J. Martínez, Chem. Phys. Lett. 460, $272(2008)$

18. A.M. Virshup, C. Punwong, T.V. Pogorelov, B.A. Lindquist, C. Ko, T.J. Martínez, J. Phys. Chem. B 113, 3280 (2009)

19. M. Boggio-Pasqua, G. Groenhof, J. Phys. Chem. B 115 , $7021(2011)$

20. C.M. Isborn, A.W. Götz, M.A. Clark, R.C. Walker, T.J. Martínez, J. Chem. Theo. Comput. 8, 5092 (2012)

21. F.F. García-Prieto, A. Muñoz Losa, M.L. Sánchez, M.E. Martín, M.A. Aguilar, Phys. Chem. Chem. Phys. 18, 27476 (2016)

22. F.F. García-Prieto, A. Muñoz Losa, I. Fdez. Galván M.L. Sánchez, M.A. Aguilar, M.E. Martín, J. Chem. Theo. Comput. 18, 737 (2017)

23. K.B. Bravaya, B.L. Grigorenko, A.V. Nemukhin, A.I. Krylov, Acc. Chem. Res. 45, 265 (2012)

24. S. Brøndsted Nielsen, J.A. Wyer (eds.), Photophysics of Ionic Biochromophores (Springer, 2013)

25. I.B. Nielsen, S. Boyé-Péronne, M.O. El Ghazaly, M.B. Kristensen, S. Brøndsted Nielsen, L.H. Andersen, Biophys. J. 89, 2597 (2005)

26. T. Rocha-Rinza, O. Christiansen, J. Rajput, A. Gopalan, D.B. Rahbek, L.H. Andersen, A.V. Bochenkova, A.A. Granovsky, K.B. Bravaya, A.V. Nemukhin, K.L. Christiansen, M. Brøndsted Nielsen, J. Phys. Chem. A 113, $9442(2009)$

27. T. Rocha-Rinza, O. Christiansen, D.B. Rahbek, B. Klærke, L.H. Andersen, K. Lincke, M.B. Nielsen, Chem. Eur. J. 16, 11977 (2010)

28. L.H. Andersen, A.V. Bochenkova, J. Houmøller, H.V. Kiefer, E. Lattouf, M.H. Stockett, Phys. Chem. Chem. Phys. 18, 9909 (2016)

29. J.N. Bull, C.S. Anstöter, J.R.R. Verlet, J. Phys. Chem. A 124, $2140(2020)$

30. I.R. Lee, W. Lee, A.H. Zewail, Proc. Nat. Acad. Sci. 103 $258(2006)$

31. J.N. Bull, C.S. Anstöter, J.R.R. Verlet, Nat. Comm. 10, $5820(2019)$

32. C.S. Anstöter, B.F.E. Curchod, J.R.R. Verlet, Nat. Comm. 11, 2827 (2020)

33. J.N. Bull, G. da Silva, M.S. Scholz, E. Carrascosa, E.J. Bieske, J. Phys. Chem. A 123, 4419 (2019)

34. G.A. Eiceman, Z. Karpas, H.H. Hill, Ion Mobility Spectrometry, 3rd edn. (CRC Press, 2013)

35. J.N. Bull, J.T. Buntine, M.S. Scholz, E. Carrascosa, L. Giacomozzi, M.H. Stockett, E.J. Bieske, Faraday Discuss. 217, 34 (2019)

36. B.D. Adamson, N.J.A. Coughlan, P.B. Markworth, R.E. Continetti, E.J. Bieske, Rev. Sci. Instr. 85, 123109 (2014)

37. J.N. Bull, M. Scholz, E. Carrascosa, G. da Silva, E.J. Bieske, Phys. Rev. Lett. 120, 223002 (2018)

38. J.N. Bull, C.W. West, C.S. Anstöter, G. da Silva, E.J. Bieske, J.R.R. Verlet, Phys. Chem. Chem. Phys. 21, 10567 (2019)

39. M.J. Frisch, G.W. Trucks, H.B. Schlegel, G.E. Scuseria, M.A. Robb, J.R. Cheeseman, G. Scalmani, V. Barone, 
B. Mennucci, G.A. Petersson, H. Nakatsuji, M. Caricato, X. Li, H.P. Hratchian, A.F. Izmaylov, J. Bloino, G. Zheng, J.L. Sonnenberg, M. Hada, M. Ehara, K. Toyota, R. Fukuda, J. Hasegawa, M. Ishida, T. Nakajima, Y. Honda, O. Kitao, H. Nakai, T. Vreven, J.A. Montgomery, Jr., J.E. Peralta, F. Ogliaro, M. Bearpark, J.J. Heyd, E. Brothers, K.N. Kudin, V.N. Staroverov, R. Kobayashi, J. Normand, K. Raghavachari, A. Rendell, J.C. Burant, S.S. Iyengar, J. Tomasi, M. Cossi, N. Rega, J.M. Millam, M. Klene, J.E. Knox, J.B. Cross, V. Bakken, C. Adamo, J. Jaramillo, R. Gomperts, R.E. Stratmann, O. Yazyev, A.J. Austin, R. Cammi, C. Pomelli, J.W. Ochterski, R.L. Martin, K. Morokuma, V.G. Zakrzewski, G.A. Voth, P. Salvador, J.J. Dannenberg, S. Dapprich, A.D. Daniels, Ö. Farkas, J.B. Foresman, J.V. Ortiz, J. Cioslowski, D.J. Fox. Gaussian 16 Revision B.01. Gaussian Inc. Wallingford CT 2016

40. F. Neese, WIRES: Comp. Mol. Sci. 2, 73 (2012)

41. J.D. Chai, M. Head-Gordon, Phys. Chem. Chem. Phys. 10, $6615(2008)$

42. J.T.H. Dunning, Jr., J. Chem. Phys. 90, 1007 (1989)

43. C. Riplinger, B. Sandhoefer, A. Hansen, F. Neese, J. Chem. Phys. 139, 134101 (2013)

44. I. Campuzano, M.F. Bush, C.V. Robinson, C. Beaumont, K. Richardson, H. Kim, H.I. Kim, Anal. Chem. 84, 1026 (2012)

45. B.H. Besler, K.M. Merz, Jr., P.A. Kollman, J. Comp. Chem. 11, 431 (1990)

46. J.N. Bull, M.S. Scholz, N.J.A. Coughlan, A. Kawai, E.J. Bieske, Anal. Chem. 88, 11978 (2016)

47. E. Carrascosa, J.N. Bull, M.S. Scholz, N.J.A. Coughlan, S. Olsen, U. Wille, E.J. Bieske, J. Phys. Chem. Lett. 9, $2647(2018)$

48. J.N. Bull, E. Carrascosa, N. Mallo, M.S. Scholz, G. da Silva, J.E. Beves, E.J. Bieske, J. Phys. Chem. Lett. 9, 665 (2018)

49. S. Poyer, C. Comby-Zerbino, C.M. Choi, L. MacAleese, C. Deo, N. Bogliotti, J. Xie, J.Y. Salpin, P. Dugourd, F. Chirot, Anal. Chem. 89, 4230 (2017)

50. E.A. Mason, E.W. McDaniel, Transport Properties of Ions in Gases (John Wiley \& Sons, Ltd, 2005), chap. 5. Kinetic Theory of Mobility and Diffusion, pp. 137-224

51. F. Bureš, RSC Adv. 4, 58826 (2014)

52. G. Papadopoulos, A. Svendsen, O.V. Boyarkin, T.R. Rizzo, Faraday Discuss. 150, 243 (2011)

53. B. Bellina, J.M. Brown, J. Ujma, P. Murray, K. Giles, M. Morris, I. Compagnon, P.E. Barran, Analyst 139, $6348(2014)$

54. S. Warnke, C. Baldauf, M.T. Bowers, K. Pagel, G. von Helden, J. Am. Chem. Soc. 136, 10308 (2014)

55. A.L. Simon, F. Chirot, C.M. Choi, C. Clavier, M. Barbaire, J. Maurelli, X. Dagany, L. MacAleese, P. Dugourd, Rev. Sci. Instrum. 86, 094101 (2015)

56. O. Hernandez, S. Isenberg, V. Steinmetz, G.L. Glish, P. Maitre, J. Phys. Chem. A 119, 6057 (2015)

57. S.J.P. Marlton, B.I. McKinnon, B. Ucur, A.T. Maccarone, W.A. Donald, S.J. Blanksby, A.J. Trevitt, Faraday Discuss. 217, 453 (2019)

58. N.J.A. Coughlan, P.J.J. Carr, S.C. Walker, C. Zhou, M. Guna, J.L. Campbell, W.S. Hopkins, J. Am. Soc. Mass Spectrom. 31, 405 (2020) 
Noname manuscript No.

(will be inserted by the editor)

Electronic Supplementary Material for

'Action Spectroscopy of Deprotomer-Selected Hydroxycinnamate Anions'

James N. Bull · Jack T. Buntine · Eduardo

Carrascosa - Mark H. Stockett - Evan J.

Bieske

J. N. Bull

School of Chemistry, Norwich Research Park, University of East Anglia, Norwich NR4 7TJ,

United Kingdom

J. T. Buntine \& E. J. Bieske

School of Chemistry, University of Melbourne, Parkville, VIC 3010, Australia

E. Carrascosa

Laboratoire de Chimie Physique Moléculaire, École Polytechnique Fédérale de Lausanne, EPFL SB ISIC LCPM, Station 6, CH-1015 Lausanne, Switzerland

M. H. Stockett

Department of Physics, Stockholm University, SE-10691 Stockholm, Sweden 


\section{S1 Photoisomer assignments}

The photoaction ATDs for $(E)-\mathrm{CA}^{-}\left(m \mathrm{O}^{-}\right),(E)-\mathrm{CA}^{-}\left(\mathrm{COO}^{-}\right)$and $(E)-\mathrm{FA}^{-}$ $\left(\mathrm{COO}^{-}\right)$in Fig. 3 and 5 in the paper indicate formation of a photoisomer. In this section we demonstrate that the photoisomer has an arrival time within $0.03 \mathrm{~ms}$ and collision cross-section within $1 \AA^{2}$ of the corresponding para-phenoxide deprotomer. In Fig. S1 the dashed traces are photaction ATDs from the paper, i.e. the isomers are separated in the first drift region, selected using the BradburyNielsen gate and then exposed to a pulse of light. In a second measurement, the source ion gate was opened completely to transmit all ions, while pulsing the Bradbury-Nielsen gate. This allowed the electrosprayed ions to separate in only the second drift region, yielding the solid ATDs in Fig. S1. Comparison between each set of traces confirms that the main photoisomer ATD peak has an arrival time within $0.03 \mathrm{~ms}$ of the ATD peak assigned to the corresponding para-phenoxide deprotomer, strongly suggesting they are the same species.
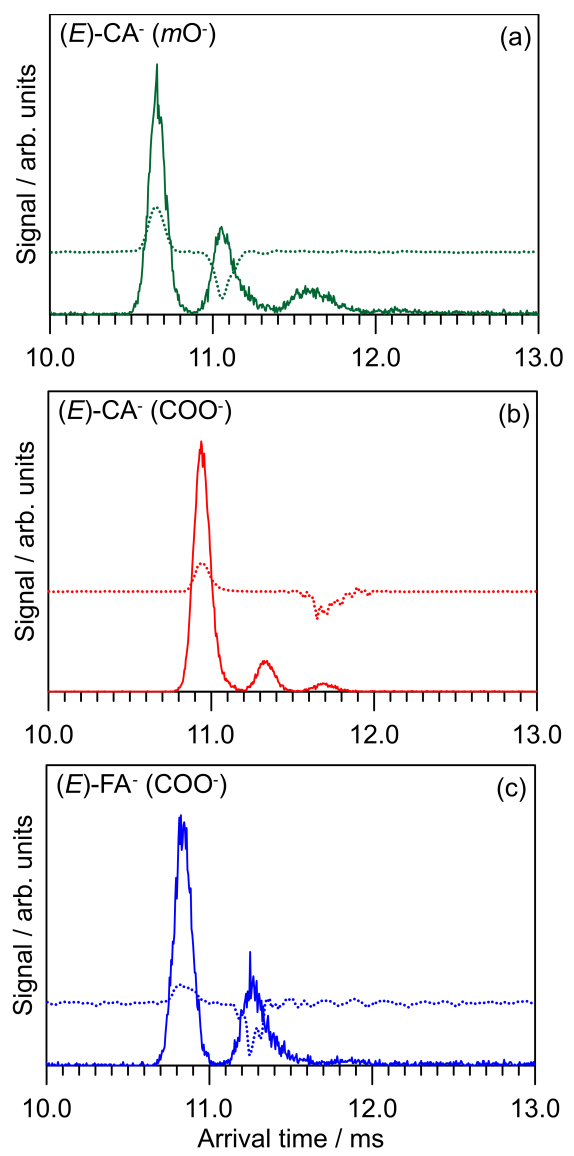

Fig. S1 ATDs (solid) and photoaction ATDs (dashed) confirming that the photoisomers for (a) $(E)-\mathrm{CA}^{-}\left(m \mathrm{O}^{-}\right)[370 \mathrm{~nm}],(\mathrm{b})(E)-\mathrm{CA}^{-}\left(\mathrm{COO}^{-}\right)[350 \mathrm{~nm}]$ and $(\mathrm{c})(E)-\mathrm{FA}^{-}\left(\mathrm{COO}^{-}\right)$ $[350 \mathrm{~nm}]$ are consistent with the corresponding para-phenoxide deprotomers. 